\title{
Cuban Youth Promote Healthier Diet through Art
}

\section{Conner Gorry MA}

Art, education, health and nutrition: encouraging healthy eating at an early age is central to the World Food Programme's (WFP) goals. To this end, using art as a learning and communications tool, the program sponsors WFP in Action, a drawing contest open to youngsters 5-18 years old. Cuba has participated in the contest nationally since the 1990s, and since 2002 has sent a selection of drawings annually to the international competition at WFP headquarters in Rome.

In the 2018 edition of the contest, international judges received 5 drawings from each of 20 participating countries. Applying criteria of esthetic appeal, originality and artistic quality, they awarded 20 prizes. Four of the five drawings from Cuba were among the international prize winners. The WFP reproduces prize-winning images in calendars, t-shirts, and other materials to promote their programs and raise funds towards ending world hunger and child malnutrition.

WFP began its collaboration with Cuba in 1963, providing emergency relief after Hurricane Flora devastated the island's eastern provinces. Today, WFP programs in Cuba aim to boost food and nutritional security among the country's most vulnerable populations, strengthen the food supply chain with an emphasis on high-protein beans (a Cuban dietary staple) and consolidate community resiliency and responsiveness in disaster risk management.

MEDICC Review is pleased to reproduce this year's four winning drawings by Cuban children-each of whom hails from a different province.

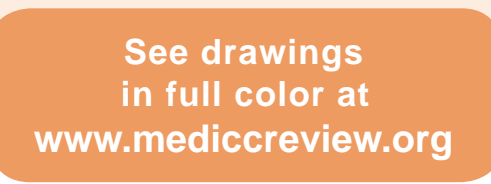

The Vitamin Machine. Leandro Martínez Mirabal, 11 years, Consolación del Sur (Pinar del Río Province)

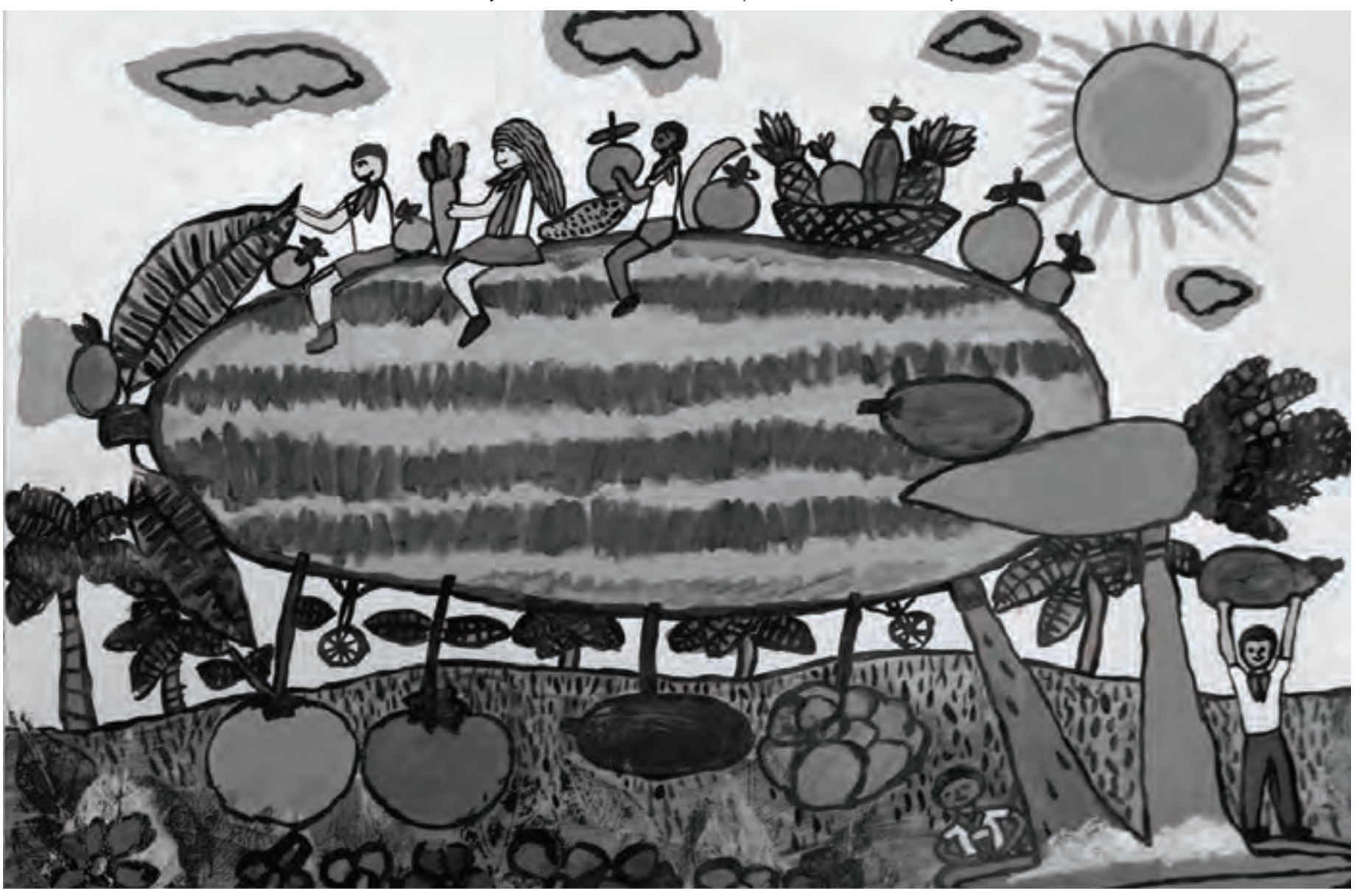




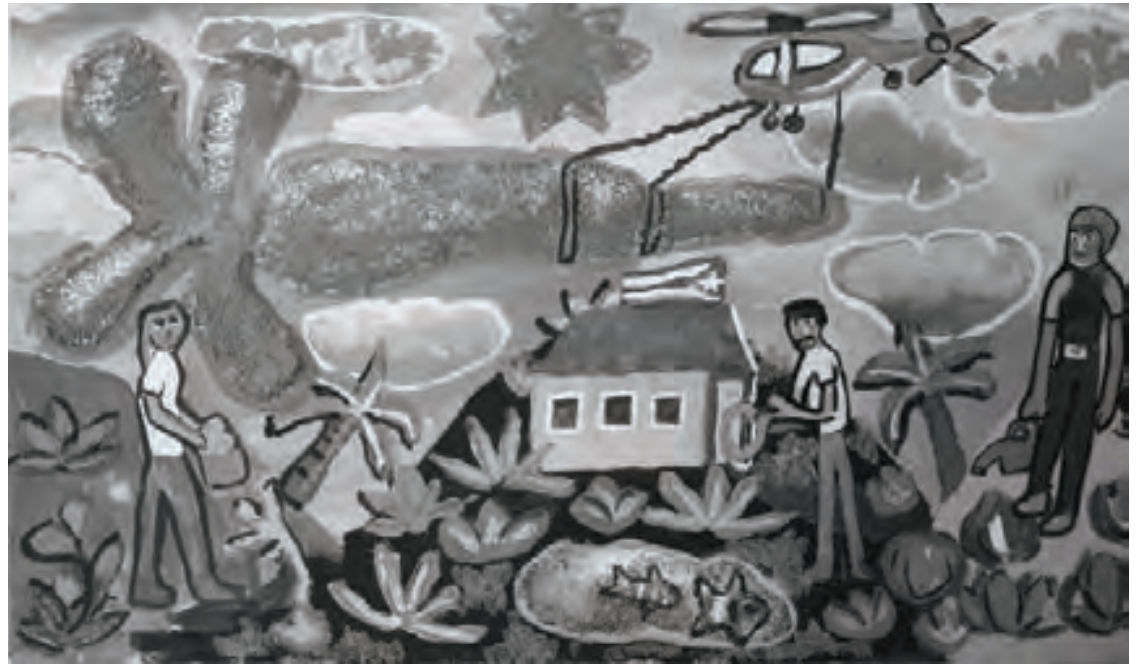

We'll Feed the Whole School with this Carrot

Yenifer Vilarino Sintes, 10 years,

Rafael Freyre (Holguín Province)

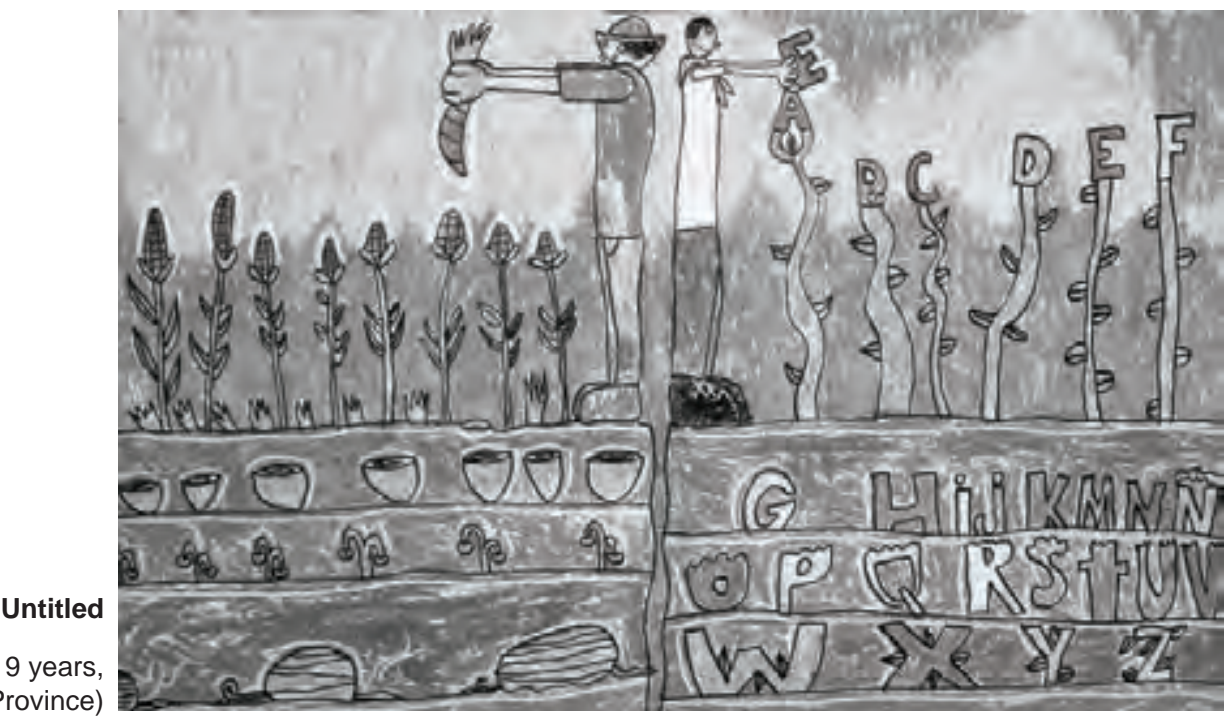

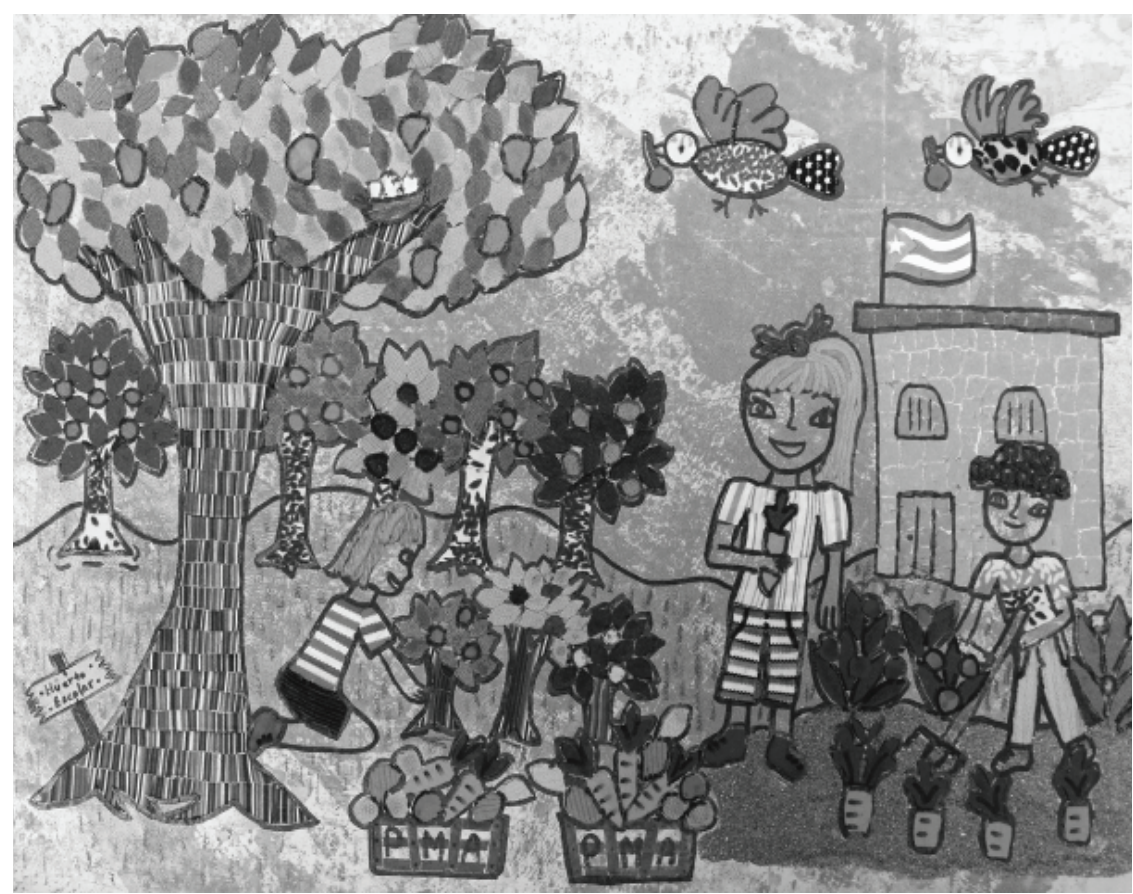

We'll Study Better with Proper Nutrition

Daniela Díaz Carmona, 11 years (Camagüey Province) 